\title{
Irus Braverman
}

\section{Saving Species, One Individual at a Time: Zoo Veterinarians Between Welfare and Conservation}

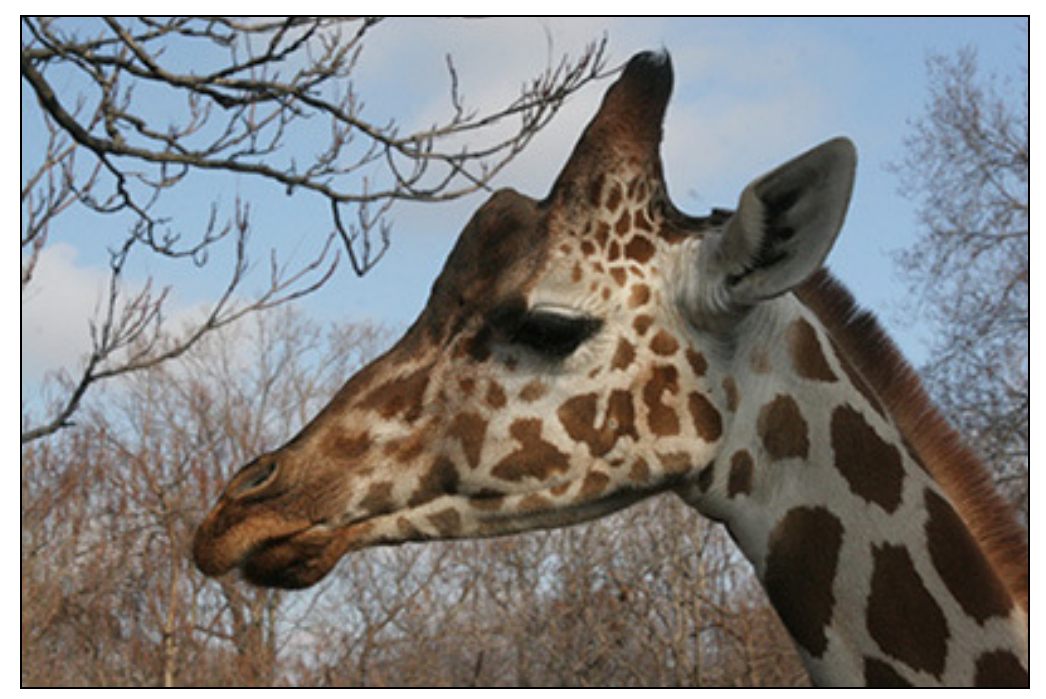

Figure 1. Reticulated giraffe at the St. Louis Zoo. Photo by Robert Lawton, Nov. 11, 2005. CC BY-SA 3.0.

"I save a species, one individual at a time."

--- Kelly Helmick (DSM). Supervisory Medical Officer, Smithsonian Conservation Biology Institute; Former President, American Association of Zoo Veterinarians (personal communication, February 15, 2016)

Who Killed Marius? On February 9, 2014, two-year old giraffe "Marius" was killed at the Copenhagen Zoo. Marius was not sick or old. He was killed because he was what zoo professionals refer to as a surplus animal. A member of the reticulated giraffe species (Giraffa amelopardalis reticulate), Marius was managed by the European Endangered species Programme, or EEP. According to Bengt Holst, scientific director at Copenhagen Zoo: "our giraffes are all part of the European breeding programme for giraffes, and as a pure reticulated giraffe, this giraffe was one of a European population of a little more than one hundred giraffes distributed over 35 European zoos." "Because he comes from a genetic line that has bred very well over the past years," Holst concluded, "there was no space for him anywhere in the population, and he was 
declared 'surplus'"' (Holst 1). In simpler terms, the Copenhagen Zoo killed Marius to prevent in-breeding within the captive breeding program (McLaughlin and Wilkinson).

The ethics of the Zoo's decision to kill Marius have been widely discussed and dissected, both in mainstream media (e.g., McLaughlin and Wilkinson; Eriksen and Kennedy; Morell; Parker) and in academia (Bekoff; Braverman, Wild Life; McCulloch and Reiss). Instead of doing more of the same, my article will highlight a rather underexplored detail of this event: the person who pulled the trigger of the Winchester rifle was the Zoo's veterinarian, Mads Bertelsen. This detail is not incidental, nor is it marginal: the role of zoo veterinarians has changed considerably in the last several decades and, in fact, they are now the only professionals authorized to conduct serious medical procedures on animals at the zoo.

The rationale behind Marius's killing is also important: the idea of a pure genetic population that will be sustainable both in the zoo and as an insurance population for the broader species is now the zoo's raison d'etre and a major component of the zoo vet's work. Although all accredited zoos would agree that no Mariuses should exist in their populations, the means for accomplishing this differ: while some zoos ensure that such animals are not born in the first place, others will kill them as they reach maturity. These differences in approach are the results of different balances that particular zoos strike regarding the welfare of various animal individuals. The zoo veterinarian is at the center of these medical and ethical debates underlying the daily operations of zoos, and is central to such decision-making practices, both as the zoo animal's major medical provider and as the one who would typically execute such decisions.

My article will explore the changing role of the zoo veterinarian (herein, the zoo vet) in contemporary zoos, and what these changes tell us about the transformation of zoo animal management more broadly. These changes are especially pronounced given that the scope of zoo veterinary medicine has transformed in recent decades to include a conservation mission that encompasses both zoo and wild animals, thereby demonstrating the erosion of the division between ex situ and in situ animal management (Braverman, Wild Life). Looking at zoos through the lens of zoo vets brings to light not only the recent transformation of this institution into one that includes conservation as its central mission (hence the vets' relatively novel focus on the sustainability of populations) but also the intensification of wildlife management outside of the zoo (hence the more individual-based, medicalized approach of managers to wild animals, and the zoo vets' increased involvement in in situ projects).

Humanimalia: a journal of human/animal interface studies

Volume 9, Number 2 (Spring 2018) 
Taking population interests into account complicates the welfare calculus that zoo vets must consider, making for a much more involved biopolitical project. In particular, I will discuss the current position of the North American zoo vet at the nexus between animal health and welfare, on the one hand, and species conservation, on the other hand. While there exists a rich scholarship on zoos generally and on particular zoo professionals such as keepers (Grazian), registrars (Braverman, “Zoo Registrars"), and curators (Berkovits), there is surprisingly little scholarly literature that focuses on zoo veterinarians, despite their centrality for this institution's function in its modern form.

This article draws on several interviews with prominent zoo vets, as well as on regulations that pertain to their work and written accounts of their experiences. I will start by briefly reviewing the institutional role of the zoo vet and a few standards that pertain to their position, especially in the United States. I will then move to document the diversity of species cared for by zoo vets, acknowledging the importance of this diversity for the very nature - indeed, the survival - of the zoo as an institution of captivity, and highlighting the unique challenges that vets face as the exclusive medical caregivers of this varied assembly. Next, I will discuss the tensions between individualand species-focused welfare and conservation. Finally, I will discuss three areas in which the work of vets purportedly advances conservation. I will conclude with a call to scholars in the social sciences and the humanities to further explore the work of zoo veterinarians.

The Zoo Veterinarian: An Institutional Context. The story of veterinary medicine dates back to Urlugaledinna, who lived in Mesopotamia in 3000 BCE and was an expert in healing animals (RCVS). The word veterinary likely originates from the Latin veterinae, which means "working animals" (but see The Veterinary Student 6). The ancient Israelites, Egyptians, and Indians were already familiar with various forms of animal diseases. Moses established a system of meat inspection and Egyptian hieroglyphs record the uses of herbs to treat and promote good health in domesticated animals. The Kahun Papyrus from Egypt dates back to 1900 BCE. Vedic literature, which was written in India at around 1500 BCE, refers to India's first Buddhist king, Asoka, who defines two kinds of medicine: one for humans and the other for animals (Cole). Both texts are likely the first written accounts of veterinary medicine. Much later, Hippocrates (460337 BCE) described hydrothorax in oxen, sheep, and swine, and mentioned the dislocation of the hip joint of cattle following a lean winter, and Aristotle (384-326 BCE) discovered a few diseases of swine, dogs, cattle, horses, asses, and elephants. Vegetius, who wrote in the fifth century $\mathrm{CE}$, is generally considered the father of veterinary medicine for his extensive writings on diseases of horses and cattle (Wilkinson 13;

Irus Braverman -- Saving Species, One Individual at a Time: Zoo Veterinarians Between Welfare and Conservation 
Figure 2). Since then, there have been numerous literary references to veterinary practices. However, it was only with the founding of the veterinary school in France by Claude Bourgelat in 1761 that the veterinary profession officially started (RCVS.).

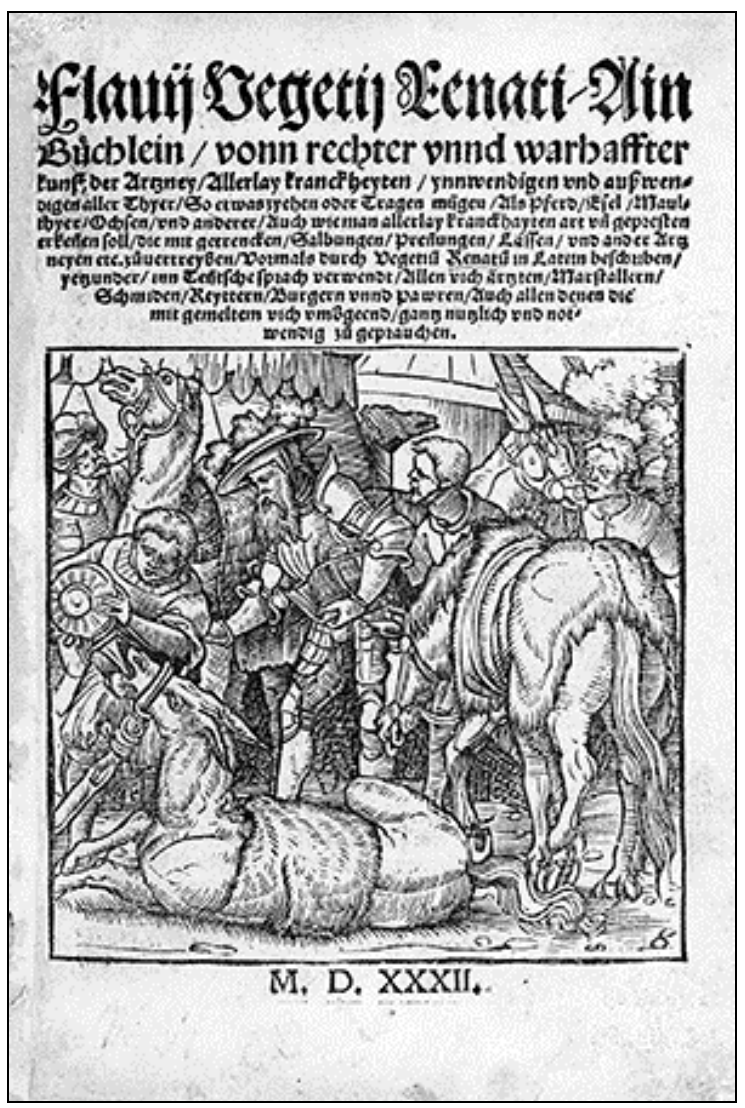

Figure 2. Title page of the first German edition of Vegetius's Veterinary Art (Wellcome Institute Library, London). Wikipedia commons.

The modern profession of the zoo veterinarian is relatively new among western clinical medical practices; it is situated between the domestic and farm veterinarian, on the one hand, and the wildlife biologist, on the other hand. The first recorded zoo veterinarian, Charles Spooner, was appointed to the London Zoo in 1829. In the United States, the first part-time zoo veterinarian was H. Amling Jr. at the Bronx Zoo in 1900. Zoo veterinarians started meeting separately in the Association of Veterinary Medicine in 1948, and in 1968 formed their own organization: the American Association of Zoo Veterinarians, or AAZV (Fowler).

Humanimalia: a journal of human/animal interface studies

Volume 9, Number 2 (Spring 2018) 
The AAZV is the professional association for individuals and institutions who apply the principles of comparative veterinary medicine to zoo and wildlife species. With more than 1,000 individual and institutional members from 60 different countries, the AAZV provides advocacy, collaboration, and partnerships for combined efforts in sustaining and improving the well-being of wildlife in all habitats ("About Us"). AAZV members work in clinical zoo medical practices, diagnostic laboratories, reproductive and pathological laboratories, pharmaceutical companies, and a wide range of governmental health and wildlife management agencies throughout the world. Kelly Helmick is Supervisory Medical Officer at the Smithsonian Conservation Biology Institute and the former president of the AAZV. According to Helmick:

the AAZV is an established leadership resource for the care of exotic zoo species, provides resources for members, but also serves as a body of experts for veterinarians looking for more information on exotic species, accrediting or legislating bodies, and affiliated organizations who may reach out to us from time to time for our expert opinions on various matters that touch on exotic wildlife health and welfare. (personal communication, December 20, 2017)

If until the latter part of the twentieth century the health of zoo animals was administered by a variety of zoo professionals, and especially by zoo keepers, contemporary laws and standards increasingly identify the zoo veterinarian as the exclusive medical provider for zoo animals. The first AAZV bylaws were written in 1974 and most recently approved in 2017. According to the 2009 AAZV Guidelines for Zoo and Aquarium Veterinary Medical Programs and Veterinary Hospitals, "zoological parks and aquariums have humane and legal obligations to provide proper husbandry, veterinary medical treatment, and preventive medical programs for their animals" (2). To achieve this goal, "zoos and aquariums in the United States are required to employ an attending veterinarian who will provide adequate veterinary care for the animal collection and to assure that certain minimal standards of veterinary care are in place according to the Animal Welfare Act of 1966" (2). ${ }^{1}$ Specifically, the guidelines state that "surgery can only be performed by a veterinarian," and that "all zoos and aquariums must have an on-site area available for minor surgical procedures" (6). These regulatory requirements frame the work of the zoo veterinarian, configuring the obligation of every zoo member institution in the United States to have a veterinarian on duty.

Irus Braverman -- Saving Species, One Individual at a Time: Zoo Veterinarians Between Welfare and Conservation 
The guidelines also situate the zoo vet as operating within the dual framework of welfare and conservation. According to Article II (5), one of the AAZV's major objectives is "to promote the general welfare and conservation of captive and freeranging wildlife" (AAZV, 2012, p. 1). The objective of caring for both welfare and conservation, which is central to the work of zoo vets, is best reflected in former AAZV President Kelly Helmick's statement, quoted in the epigraph, that she saves species one animal at a time. Rob Hilsenroth, current director of AAZV, tells me along these lines that, "while the effort is on the individual animals, the overview is saving species" (personal communication, February 15, 2016). Working under the dual welfareconservation mission is arguably not only the prerogative of the zoo vet, but also represents the broader platform of contemporary zoos, which include conservation as a core part of their agenda. Indeed, as I have argued elsewhere (Braverman, Zooland), in the last several decades zoos and aquariums (while I have focused on accredited North American zoos, this is mostly true of accredited zoos in other regions, too) have shifted their mission from entertainment to promoting conservation and education. Exhibits with concrete and metal cages have largely been replaced by nature "immersion" designs, and the human stance of domination over animals has been redefined as one of care and stewardship (Braverman, op. cit. 5).

The accredited zoo's new emphasis on conservation and care now calls for collaborative management of specific animals among zoo institutions through animal programs such as the Species Survival Plans (SSPs) in North America and the EEPs in Europe. There are currently nearly 500 SSP programs, grouped according to taxa for management under a Taxon Advisory Group (TAG). According to the American Association of Zoos and Aquariums (AZA), each SSP "is responsible for developing a comprehensive population Studbook and a Breeding and Transfer Plan which identifies population management goals and recommendations to ensure the sustainability of a healthy, genetically diverse, and demographically varied AZA population" ("Species Survival Plan"). SSPs are collaborative breeding programs that coordinate between what effectively becomes a "zooland" - a network of all relevant institutions and animals under one management platform. A variety of population management strategies serve both to enhance the sustainability within zooland and to create healthy populations for possible "reintroductions" into the "wild." Such populations of zoo animals are often referred to as insurance populations.

Zoo veterinarians perform a central role in the elaborate administrative apparatus of accredited zoos. In North America, the AZA guidelines are the required industry standard for 230 accredited institutions around the country. According to these

Humanimalia: a journal of human/animal interface studies

Volume 9, Number 2 (Spring 2018) 
guidelines, a Veterinary Advisor must be assigned to each SSP, while the Veterinary Advisory Group (VAG) coordinates between the Advisors ("Guidelines"). The guidelines identify a vast set of tasks for the Veterinary Advisor, ranging between responsibility for medical protocols, health provisions, disease prevention, monitoring and reporting, and providing information on conservation programs (ibid.). As I will discuss shortly, the expertise of Veterinary Advisors can extend beyond that of captive zoo animals to incorporate health care for in situ populations (Deem 7).

Caring for Diverse Zoo Animals. The modern zoo institution prides itself on exhibiting and managing a large variety of animals, and on adequately sustaining such animals in terms of their health and other needs. Accordingly, perhaps the most notable feature of the zoo vets' work is their care for such an incredibly diverse range of species, in what is usually a relatively small urban space. In Helmick's words: "You might see a hummingbird first thing in the morning and an elephant last thing in the afternoon and everything else in between. And you need to know what you're doing" (personal communication, February 15, 2016). Helmick emphasizes how this diversity carries over into medical practice: "we're the last of the general practitioner. I am an anaesthesiologist, I am a pathologist, I am an internist, I am a surgeon, I am an epidemiologist. I am an ophthalmologist, a cardiologist, and a neurologist" (ibid.).

Michael Adkesson is a zoo vet at the Brookfield Zoo in Chicago. Figures 3 through 7 relay the vast variety of animals he deals with on a daily basis, from polar bears through gorillas and penguins to pangolins and grey wolves. "For some animals, it's very easy," Adkesson tells me, explaining that "with zebras, your equine base is very similar and very solid; for great apes and even some of your smaller primates, it's [a] very close correlation to human medicines; same thing for tigers and cats and wolves and dogs and that sort of thing." However, when it comes to aardvarks and kangaroos, he continues, "there's just not a really close correlation to the domestic animal or the human animal data that provides you with information on how to treat those diseases and what drugs are going to be most effective and how they metabolize those drugs and what dosage is most appropriate" (personal communication, March 15, 2016).

Leigh Clayton, director of animal health and welfare at Baltimore's National Aquarium, is the lead vet responsible for the health and wellbeing of 15,000 animals from 800 different species. The challenge, in her words, is "to take facts you know from one species and then apply them to another species" (Brogan). Clayton explains. For example, how she anaesthetizes, $x$-rays, and operates on a fish, emphasizing that most fish are not traumatized by the medical processes and go right about their day upon

Irus Braverman -- Saving Species, One Individual at a Time: Zoo Veterinarians Between Welfare and Conservation 
returning to their aquariums. The difficult cases are with those fish in large containers who cannot be trained to come to the vet. "Schooling fish are hardest to work with as individuals," she says. Octopuses can be challenging, too, she adds (see, e.g., Montgomery).

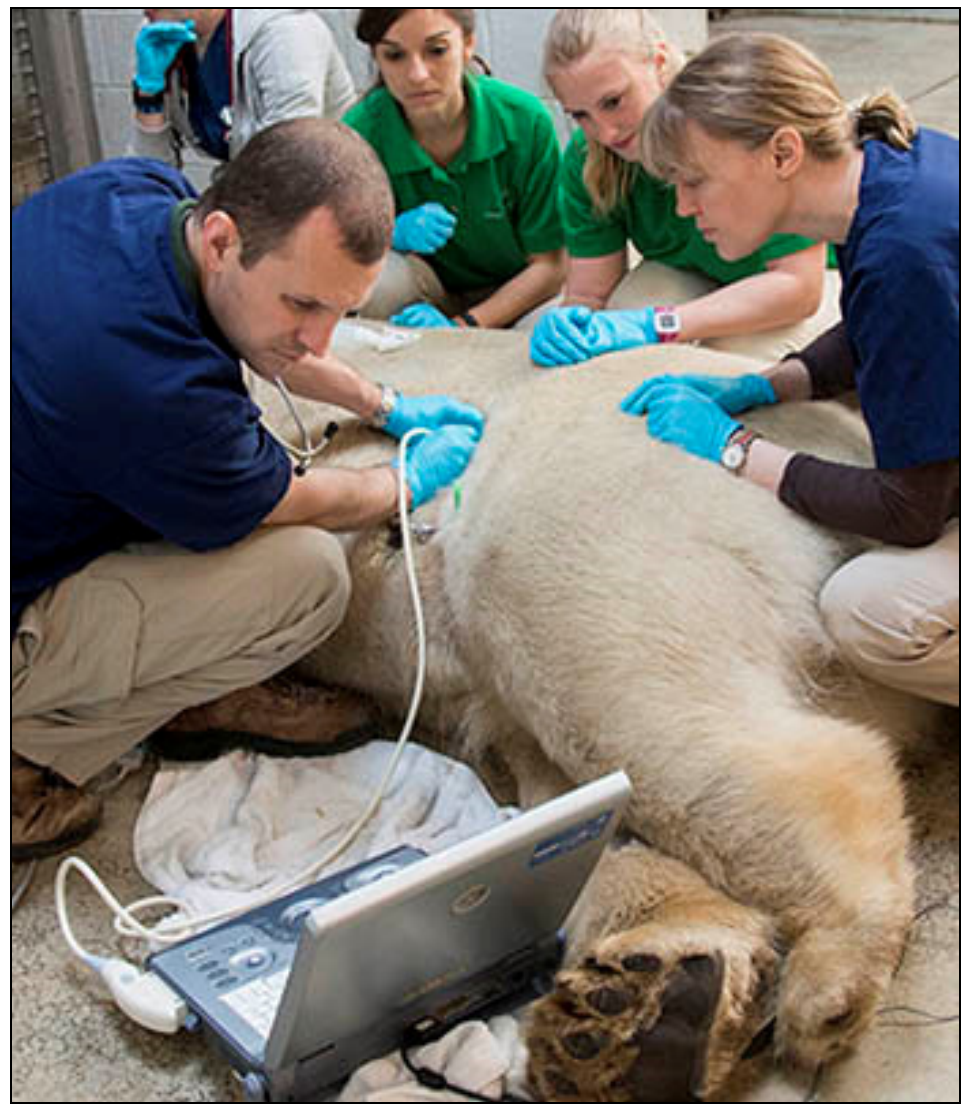

Figure 3. As part of a wellness examination, Adkesson performs an abdominal ultrasound on a polar bear to evaluate organs such as the liver and kidneys for any evidence of disease. Courtesy of Michael Adkesson, May 2016.

Humanimalia: a journal of human/animal interface studies

Volume 9, Number 2 (Spring 2018) 


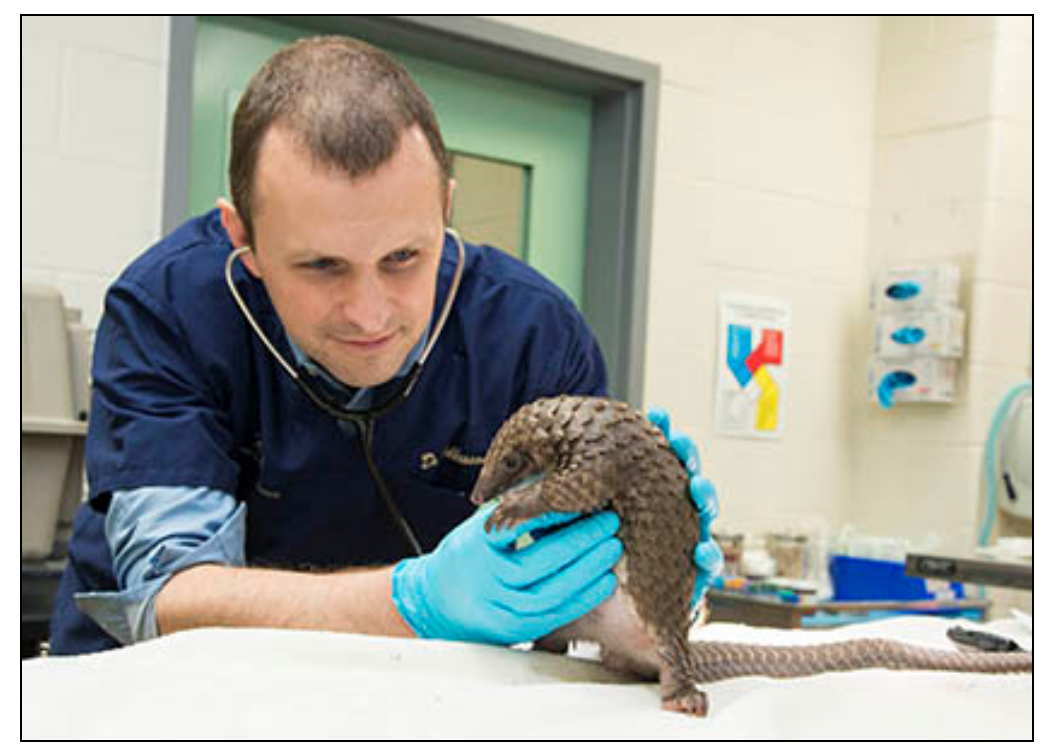

Figure 4. Adkesson listens to the heart of a white-bellied tree pangolin as part of a regular veterinary check-up, May 2016. Pangolins are rapidly facing extinction in the wild due to illegal hunting and habitat loss. According to Adkesson, pangolins in zoos provide an opportunity to better understand the health and physiology of these rarely studied animals, which can in turn help advance sound conservation policies. Courtesy of Michael Adkesson.

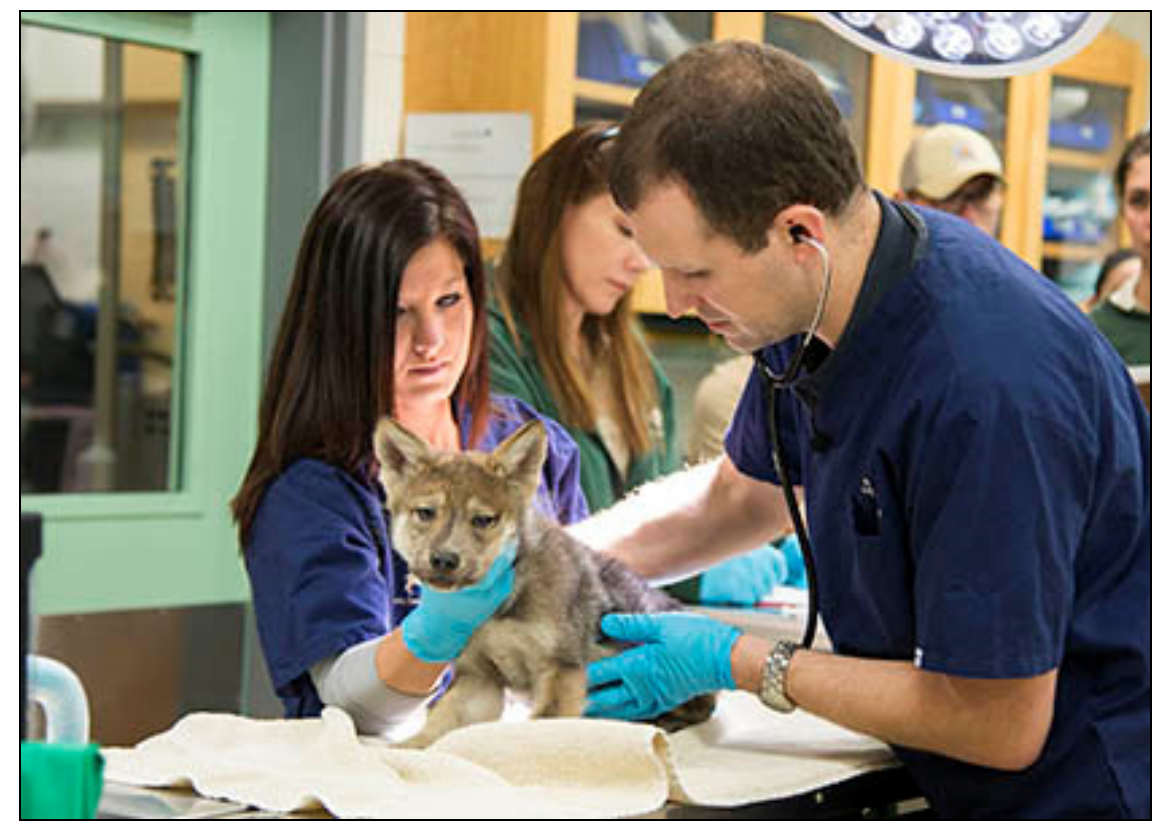

Figure 5: Adkesson and veterinary technician examine a Mexican grey wolf pup as part of a health check-up, June 2016. The last five survivors of this subspecies were bred in captivity and their progeny reintroduced in 1998. At the beginning of 2017, experts announced that only 113 Mexican grey wolves were counted in the wild. Courtesy of Michael Adkesson.

Irus Braverman -- Saving Species, One Individual at a Time: Zoo Veterinarians Between Welfare and Conservation 


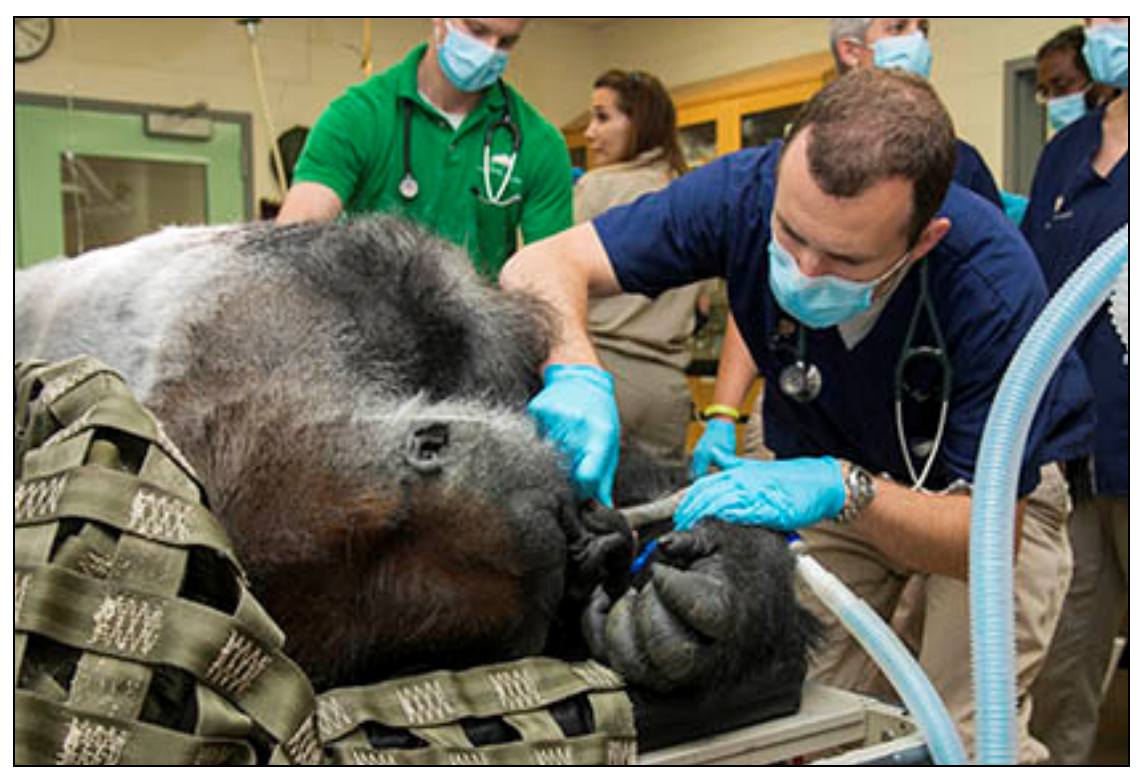

Figure 6. Adkesson examines the teeth of a silverback western lowland gorilla as part of a preventative healthcare examination, August 2015. Zoo veterinarians must be adept in multiple specialty areas of medicine and surgery, including dentistry. Dental care and cleaning is part of every standard examination, Adkesson tells me. Courtesy of Michael Adkesson.

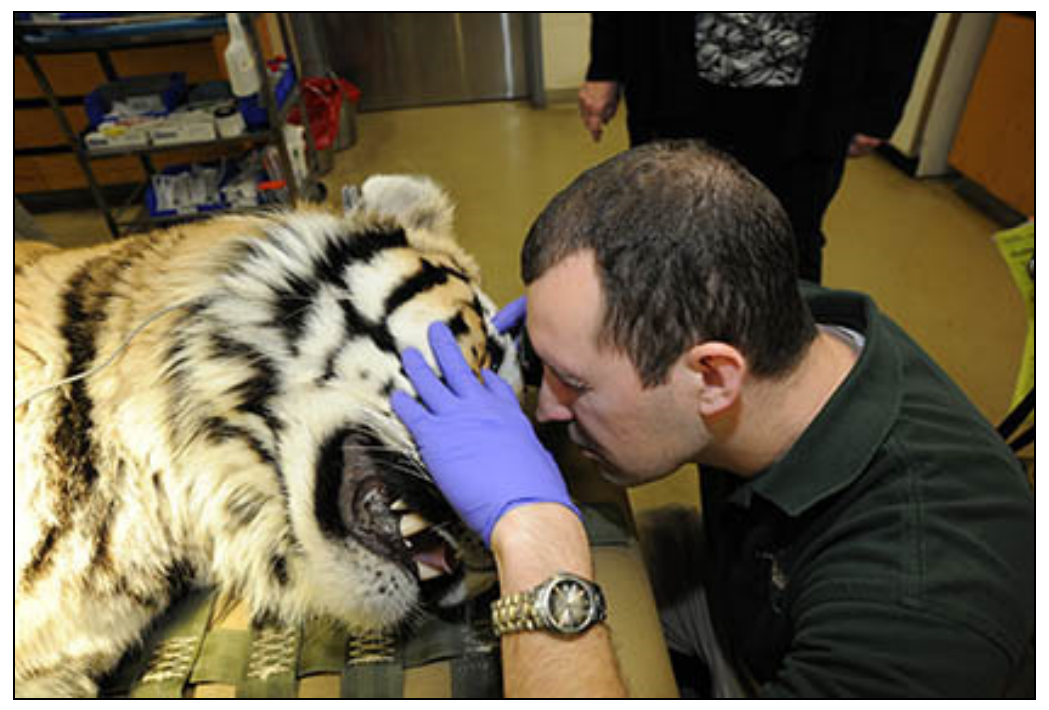

Figure 7. Adkesson examines the eye of an Amur tiger during a routine veterinary examination. Courtesy of Michael Adkesson, January 2013.

In addition to the expansive range of medical knowledge that zoo veterinarians must exercise on a daily basis and the safety challenges inherent in treating wild animals, the difficulty of the vets' work is exacerbated by scant medical knowledge about most

Humanimalia: a journal of human/animal interface studies

Volume 9, Number 2 (Spring 2018) 
wildlife species, which have a short history of individual care by humans. As a result, zoo vets must also be creative. Helmick explains:

There's no book on bear neurology. You can find one of dogs and cats and horses, but nobody wrote the book on how to do a reproductive evaluation on a chuckwalla, which is a type of lizard. So filling those gaps, making those inferences from other species, and making those leaps of faith and having a successful outcome - is why I like doing what I am doing. (personal communication, February 15, 2016)

One such leap of faith occurs whenever zoo vets must figure out the appropriate medications, and their quantity, for zoo animals. Traditionally, humans didn't treat wild animals with drugs; "drugs were made for humans and domestic animals" (ibid.). There are no allopathic medical pills for elephants or bears. To treat many zoo animals, the vets must thus "compound" drugs - that is, source pharmaceuticals in larger doses and devise other clever ways of dosing for animals under their care. Helmick describes a strategy she used for a hippopotamus she treated who suffered from skin infection. Her pharmacist "came up with something that we lovingly call hippo balls - ... 50 grams of amoxicillin in a peanut butter ball half the size of my fist, as opposed to 350 small amoxicillin tablets that require darting the animal" (ibid.).

At the zoo, safety is always a prime concern (Zooland 142-5), adding another layer of complexity to the work of zoo vets. Helmick discusses the challenges of ensuring the safety of both zoo animals and human staff and visitors:

A follow-up visit on a grizzly bear usually requires some type of immobilization, and that's a welfare issue for my patient. That's [also] a safety concern for the staff that I work for. I have to get that animal safely anaesthetized, transferred across the zoo, usually when the public is there [i.e. during working hours], and safely into my hospital, get all my diagnostics, make a treatment plan [so] that I can administer as many treatments as I can under anaesthesia, and [finally] return the animal safely to his bedroom and recover him. (personal communication, February 15, 2016; see, e.g., Figures 8 \& 9)

Irus Braverman -- Saving Species, One Individual at a Time: Zoo Veterinarians Between Welfare and Conservation 


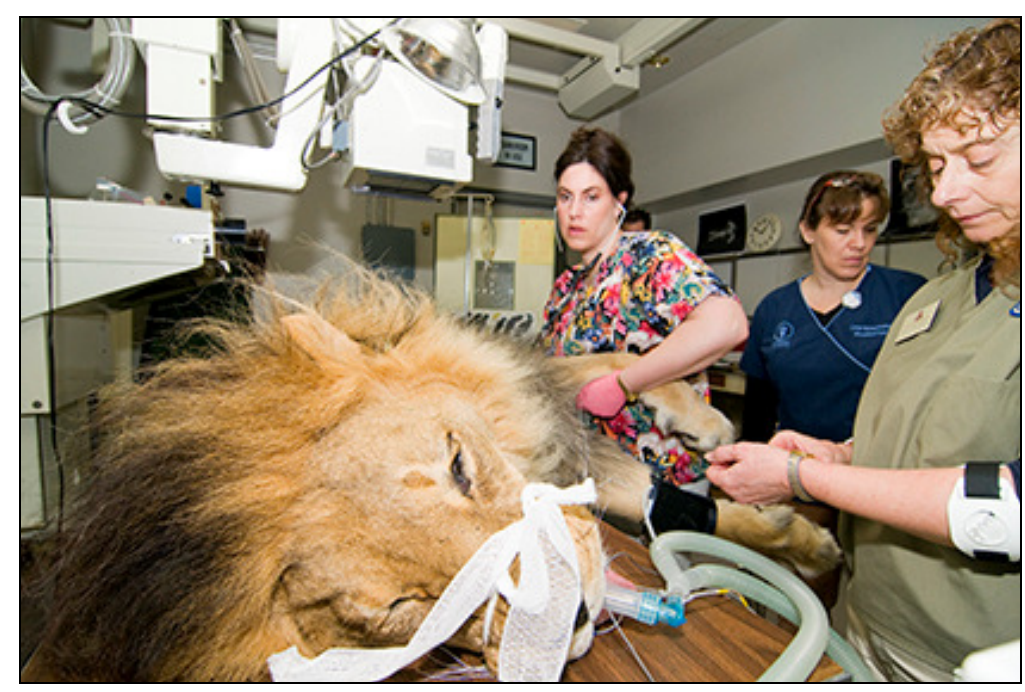

Figure 8. Helmick (left) listens to the heart of an immobilized lion at the Woodland Park Zoo in Seattle, Washington. “There are inherent safety challenges that a zoo veterinarian must meet when immobilizing and examining a large exotic felid such as this lion, which weighed 178 kilograms," Helmick tells me. "Techniques for drug administration that minimize stress to the patient and ensure complete injection of all immobilizing agents often require a significant investment of veterinary and animal care staff time. Because immobilization drugs are marketed for smaller domestic dogs and cats, zoo veterinarians often use specialized products that provide the same drugs but in a concentrated form, to minimize the injection volume and ensure complete administration of all immobilizing agents" (email communication, December 20, 2017). Photo credit: Ryan Hawk, Woodland Park Zoo.

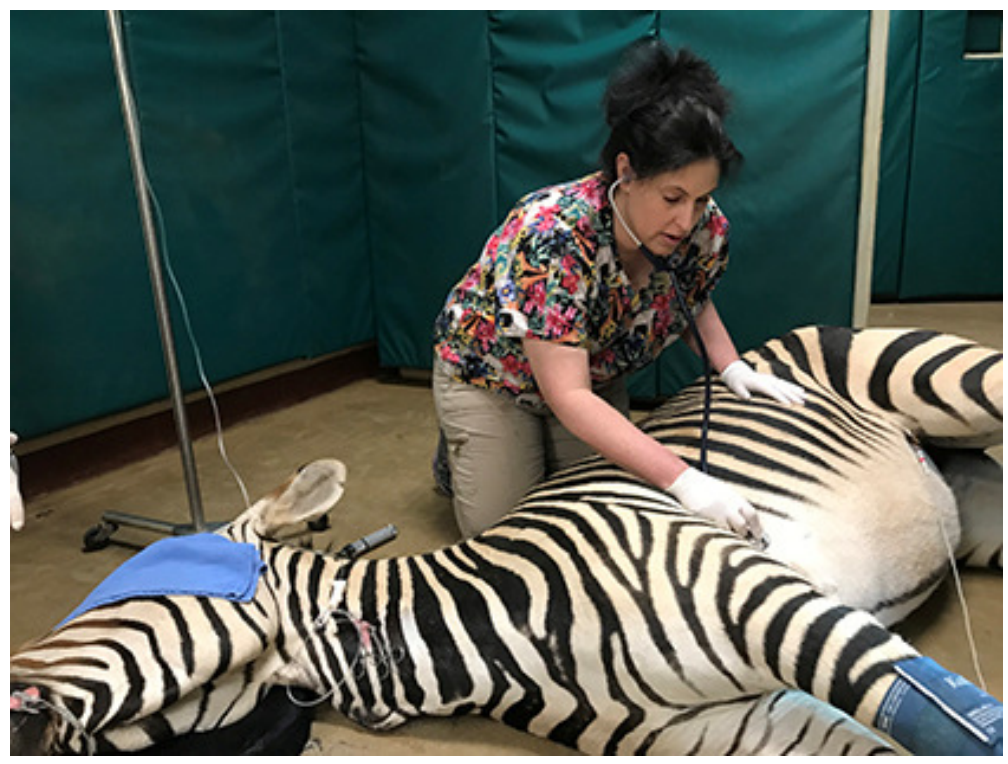

Figure 9. Helmick monitors an anesthetized Hartman's mountain zebra (Equus zebra hartmannae) during a routine examination at the Smithsonian Conservation Biology Institute, Front Royal, VA. She tells me that, "While closely related to the domestic horse, zebras are wild animals and retain wild behaviors and responses even under human care. While a routine examination on a domestic horse can often be accomplished on an awake animal, zebras are dangerous animals and require anaesthesia to collect blood, examine feet, and perform other routine diagnostics, such as palpation. Zoo veterinarians must take what they learned about domestic species and learn how to adapt that knowledge to the unique species in their care" (email communication, December 20, 2017). Photo credit: Dr. Budhan Pukazhenthi.

Humanimalia: a journal of human/animal interface studies

Volume 9, Number 2 (Spring 2018) 
The zoo vet's medical knowledge thus draws on and infers from medical knowledge pertaining to humans, domestic animals, and animals in the wild, embodying the interrelations among these various animals and the need for a holistic approach toward caring for all living beings, while at the same time recognizing the differences between them. The range of species that zoo vets must care for, the lack of medical information about many of these species, and the fact that the zoo vet is effectively the last of the general medical practitioners - not to mention that this job is dangerous, short-staffed, and underpaid (and thus also highly gendered) - these factors all exemplify the uniqueness of the zoo vet's work alongside the peculiarity of the modern zoo institution.

Welfare for Individuals, Welfare for Species. As medical practitioners, zoo vets have an ethical obligation to care for their animals as individuals. A few questions arise in this context, including what the animal's best welfare is, who gets to make this decision, and how to balance the welfare of different animals when they are in conflict. Lately, additional welfare interests have complicated the picture as the values of individual animal welfare are balanced with less traditional values based on the conservation status of the animal and her population and species. The rationale behind Marius's killing by the Copenhagen Zoo, for example, was that his mother would benefit from her ability to experience natural reproduction, instead of the use of contraception medications. While such a "breed-and-cull" tactic is used in many northern European zoos, the more widespread strategy for reproductive control is the use of artificial contraception. Indeed, this is how North American zoos typically avoid the need to kill larger mammals later down the line, sometimes with a considerable cost to the health of the contracepted animal (Zooland 174-7).

At the Copenhagen Zoo - which, like other accredited zoos, operates under the premise that surplus genes are undesirable in captive breeding programs - the giraffe mother's welfare interests to give birth were valued as higher than the calf's interest to continue living. Who is to decide whose welfare matters more? Kelly Helmick told me in an interview: "I' $m$ a vet, I'm licensed, and I'm accredited. [So] according to the law[s] that govern my role as a vet, I am the animal welfare expert." At the same time, "the general public might feel they're the animal welfare experts" (personal communication, February 15, 2016). The public outcry around Marius's killing is but one visible example of the "great battle of pastorship," whereby, per Michel Foucault, each group claims to be the one true caretaker of the (giraffe) flock and its individuals (Zooland 20-23).

Irus Braverman -- Saving Species, One Individual at a Time: Zoo Veterinarians Between Welfare and Conservation 
Alongside the traditional individual-focused welfare models, another important normative framework that is emerging in zoos generally, and that is applied by zoo veterinarians in their work in particular, is the perspective of populations, species, and even entire ecological systems. Under what is sometimes referred to as the "intrinsic value of nature" approach (see, e.g., Callicott; Naess), Marius's individual interest in a continued life was configured as falling short of the population's interest in sustaining its long term genetic diversity, as his genetic makeup was perceived as non-valuable for the sustainability of the zoo population. Put differently, whereas the exclusive focus of the veterinary medical world used to be on individual animals, concerns about the sustainability of entire populations are becoming increasingly important. Rob Hilsenroth, director of the AAZV, told me along these lines: "The overall goal is to look at what is best for the species that you're trying to save" (personal communication, February 15, 2016; my emphasis).

According to the advocates of the ecological approach to zoo animal management, focusing too much on the rights and welfare of individual animals can lead to serious problems at the species level, especially for imperiled species. And since such species are comprised of individual members, so this argument goes, increased inbreeding, disease, and ultimate extinction would eventually impact individual animal welfare, too - if not now, then in generations to come. How to evaluate the welfare of animals who belong to endangered species and who are no longer capable of living outside captive institutions, or without intense human management in the wild? Such difficult situations for the last members of species in existence who have become "captive for life" are becoming increasingly relevant as existing ecological systems can no longer sustain them (Braverman, Wild Life). Their status as the last members of the species matters to the management of their welfare as individuals: managing the last northern white rhino in existence, for example, is different from managing a meerkat, a barn swallow, or any other species defined as "Least Concern" by the International Union for Conservation of Nature. Philosopher Ben Minteer and ecologist Jim Collins write in this context:

Unavoidable animal welfare impacts produced as a result of high-priority and well-designed conservation research and conservation activities involving captive animals will in many cases have to be tolerated to understand the consequences of rapid environmental change for vulnerable wildlife populations in the field.... Inevitably, these changes will continue to blur the boundaries of in situ and ex situ conservation programs as a range of management activities are adopted across more or

Humanimalia: a journal of human/animal interface studies

Volume 9, Number 2 (Spring 2018) 
less managed ecological systems increasingly influenced by human activities (49).

Zoo veterinarians find themselves at the nexus between the conservation interests of species, those of their individual patients, and the limitations of zoological medicine and institutional practices. So, for example, despite the condemnation by the AZA of the culling of Marius the giraffe, the AAZV's 1998 edition "Guidelines for Zoo and Aquarium Veterinary Medical Programs and Veterinary Hospitals" already considered that euthanasia "may be necessary for ... [animals] that are surplus to breeding and exhibit needs" (11). The incident at the Copenhagen Zoo thus highlights the ongoing internal debate within the zoo community, and among zoo veterinarians in particular, about the ethics of caring for individual zoo animals within a conservation framework.

Welfare Hierarchies: Domestic, Zoo, Wild. Although the ex situ - in situ divide is increasingly blurring (Braverman, Wild Life), and with it also the distinctions between domestic and wild animals, zoo vets seem to be hanging on to certain categorical distinctions such as that between wild and pet animals. Kelly Helmick tells me in this context:

I do not confuse my pets at home with patients at the zoo. And yet I care deeply for them both and I try to put their interests forward each and every time. But I don't think people understand that animals serve a purpose ... and [that] we as human beings have a responsibility to those animals whether they're in the wild, in our homes, or at a zoo. Our responsibility to them is different [in each situation]. That's why we do more for an animal in the zoo than for an animal in the wild, in part because we can, but in part because we've taken on the responsibility for that animal - we give it its environment, we provide it with its food, and we darn well better take care of it when it's not feeling well. (personal communication, February 15, 2016)

Helmick's statement highlights both the unique status of zoo animals as existing somewhere between the categories of wild and domestic as well as the corresponding duties and responsibilities by the zoo vets, which also exist somewhere in between: stronger than those toward wild animals but weaker than for pets. ${ }^{2}$ Notably, Helmick does not refer to zoo animals by name, something she reserves to pets, instead referring to them as "patients." The name Marius, she points out, was given to the giraffe for internal identification purposes only, and wasn't intended for use by the public;

Irus Braverman -- Saving Species, One Individual at a Time: Zoo Veterinarians Between Welfare and Conservation 
tellingly, the Copenhagen Zoo's scientific director never used this name in public presentations (Parker).

The vets' guarding and reinforcing of the distinction between pet and wild animals corresponds with the overall mission of zoos to delineate and reinforce the categorical classification of animals. As I wrote elsewhere, "[t]he human need to organize and clarify animals is projected onto the space of the zoo, resulting in the separation of domesticated animals from wild animals" (Braverman, Zooland 69). The zoo's guarding of traditional animal categories also goes hand-in-hand with its guarding of notions of wilderness and pristine nature - for what would be the central rationale behind its existence if not to expose zoogoers to wild nature? (ibid.).

The difficulties of balancing the various interests and hierarchies among domestic, zoo, and wild settings and animals, especially those who belong to endangered species, are brought home by the following story that Helmick tells me. The story focuses on an instance that involved caring for injured wild Florida panthers taken from the wild and placed in human care until they were sufficiently functional in the wild. In Helmick's words:

I was in Florida, [and] we had a lot of animals passing though the hospital. I had a Florida panther living in an offsite area managed by the U.S. Fish and Wildlife Service, and I was going out weekly and treating it for fungal dermatitis before returning it to the wild. That was pretty intense. We had five-acre pens at a private facility, where we rehabilitated these animals with wild deer.... We'd make sure they could hunt before we released them back to the wild.... So there are some very intensive elements of population management and it depends on the population and the management that is required at the time. And a lot of the strategies, things that we do to help those animals, come directly from what we learn from the animals we have at the zoo. That's part of the larger role zoo animals play. (personal communication, February 15, 2016)

In this story, the medical knowledge produced by zoo vets in in situ and ex situ contexts inform each other so as to enhance the overall understanding of animals in both contexts, at the same time eroding the rigid demarcation between in situ and ex situ conservation (Braverman, Wild Life).

Humanimalia: a journal of human/animal interface studies

Volume 9, Number 2 (Spring 2018) 
Furthermore, Helmick's story demonstrates the calculus underlying the decision to place the wild deer in the panther's pen, thus serving as a tool for the rehabilitation of the latter and implying that the endangered panther's life is more valuable than that of the abundant white-tailed deer. In a follow up email communication, Helmick outlines her ethical considerations in this regard:

The deer cannot escape, [but] neither can the panther. Should [the panther] be allowed to starve?... Panthers are endangered - WTD [whitetailed deer; IB] are not. WTD are hunted by humans for food and sport. [Why is] hunting a deer with skill, weapons, and the use of feeding stations to enhance kill success acceptable, but a "welfare" decision for other humans (vets) to contain that deer so that another predator - this time, the panther - can hunt it within a large space, requiring the panther to exhibit skill and ability, isn't? Does a WTD have the "right" to not be eaten by a panther? Does the same WTD have the same right to not be hunted by a human? Humans alter panther habitat to build homes and roads and to plant crops.... Does the panther only have the "right" to hunt WTD when a human decides that the WTD can "escape" the predator?... What are the ethics of releasing a predator back to the wild without ensuring it has returned sufficiently to a level of health that will allow it to be successful in the wild? Should the vet recommend that the panther be fed canned cat food and hope for the best? What are the ethical implications of that? You wouldn't release a WTD back to the wild if you didn't asses its ability to run away; you wouldn't release an eagle back to the wild if you didn't assess its vision and flight capability; you do not return a predator to the wild until you are sure it can hunt. If you can't accept that last tenet and the ethical responsibilities that come with it then you are choosing to let the panther go extinct because of lack of human compassion, presence of human ignorance or bias, or selfishness and an inflated sense of our "ethics." (email communication, December 16, 2017)

Evidently, Helmick's everyday work as a zoo vet presents intense ethical deliberations. And although many animal welfare proponents would likely disagree with her conclusions, she does not shy away from identifying and tackling the problematic ethical issues head on. For her, the panther should be fed with captured wild deer for two accumulative reasons: first, because the panther is captive and thus humans have an enhanced responsibility for his welfare (this applies to the deer, too); second, because

Irus Braverman -- Saving Species, One Individual at a Time: Zoo Veterinarians Between Welfare and Conservation 
panthers are endangered and thus humans have an additional responsibility to save them, which includes training them to survive in the wild before their reintroduction. Constructing and negotiating such biopolitical hierarchies among different wild species and among members of the same species in wild and zoo settings are a routine matter in animal management (Braverman, "Anticipating Endangerment"; Law) and at the heart of the zoo vet's work.

Zoo Veterinarians as Conservationists. The shift of zoo animal management in accredited zoos toward conservation is recent (Braverman, Zooland). Like the zoo institution within which they operate, the zoo vet profession, too, has undergone a transformation in the last several decades. Hilsenroth describes succinctly: "It's gone from where we were in the 1950s, where it was mainly emergency medicine, then to preventative medicine, and then [to] sustainability within the zoo populations and, finally, now we're moving toward the sustainability of animals in situ" (personal communication, February 15, 2016). The transformation, according to Hilsenroth, is not only from individual to species but also from ex situ to in situ conservation.

Generally speaking, zoo vets see themselves as contributing to conservation in three ways. First, they directly participate in conservation in the wild - or in situ conservation. Second, they promote scientific knowledge about zoo animal as proxies for animals in the wild, using these animals to create databases, archives, serum banks, and, generally, to further veterinary medicine for the benefit of wild animals and humans alike. Third and finally, they purportedly contribute to conservation by reintroducing zoo animals into the wild (in a way, a more extreme form of proxy as reintroductions are performed in order to support wild populations - namely, the zoo animals support in situ conservation by themselves becoming in situ animals). To top off these three contributions, zoo vets also indirectly support conservation by caring for the animals who are then used to educate zoogoers about conservation. ${ }^{3}$ I will not discuss their role of zoo vets in conservation education here. Instead, this section will explore the three more direct contributions of zoo vets to conservation.

A growing number of zoo vets dedicate a growing part of their work to veterinary support of conservation in the wild. Research veterinarian S.L. Deem notes along these lines that, "[i]n addition to the health care provided to captive animals, zoo veterinarians today have a number of roles within in situ conservation projects that ensure the maintenance of healthy and viable free-ranging populations of wildlife" (Deem 3). Rob Hilsenroth further explains that, "to be an AZA certified zoo you have to be doing some kind of conservation initiative or funding some kind of conservation

Humanimalia: a journal of human/animal interface studies

Volume 9, Number 2 (Spring 2018) 
initiative somewhere in the world" (personal communication, February 15, 2016). In its 2015 Annual Report on Conservation Science, the AZA noted that zoos spent over 186 million dollars on field conservation projects in over 120 countries, benefitting more than 700 species, 227 of which listed as endangered or threatened under the Endangered Species Act (2).

Veterinary medicine is an increasingly important component of the zoos' in situ conservation initiatives. For example, Michael Adkesson of the Brookfield Zoo tells me about his involvement in a marine protected area in Peru: "I've been working down there since 2007 and am very intimately involved in a conservation program focused around South American fur seals, South American sea lions, and Humboldt penguins" (personal communication, March 15, 2016; see Figures 10 \& 11). Such in situ work is often related to a specific zoo exhibit or $e x$ situ conservation initiative, which the zoo vet is already well versed in. Hilsenroth explains, for example, that "if your zoo has some orangutans, you might be doing a project over in Borneo with the wild orangutans and your vet might be going over there twice a year" (personal communication, February 15, 2016). This way, in situ conservation initiatives simultaneously support and are supported by the zoo's particular strengths and resources.

But working in situ also presents new challenges for zoo vets. One of the more straightforward challenges is that the zoo's medical resources often cannot be transported to in situ locations. Adkesson explains the difficulties of working in remote areas or in developing countries: "without the very advanced equipment while at the zoo," he says, "it can feel like practicing ... fifty years in the past." "So it's a combination of trying to adapt equipment that's used in a hospital setting into a field setting, to make things run off the batteries, [and to] make things run off a solar panel" (personal communication, February 15, 2016). In addition to the technological challenges, there are also the challenges of treating wild animals in less controlled environments. Adkesson explains:

With wild animals, that animal needs to wake up from anaesthesia and recover and be able to be right back in the wild in a free-range setting. You don't necessarily have a lot of follow up care or the opportunity to intervene again, so you're really trying to do everything as safely and effectively as you possibly can, while also making sure that animal is going to have no long term deleterious effects from [the medical care]. (personal communication, March 15, 2016)

Irus Braverman -- Saving Species, One Individual at a Time: Zoo Veterinarians Between Welfare and Conservation 
Rob Hilsenroth summarizes the differences between the work of zoo vets in and ex situ, or in-zoo. At the end of the day, he tells me "in situ vet work is much more focused on the population health of a given area," while in-zoo vet work focuses more "on the health of that individual animal per se" (personal communication, March 15, 2016).

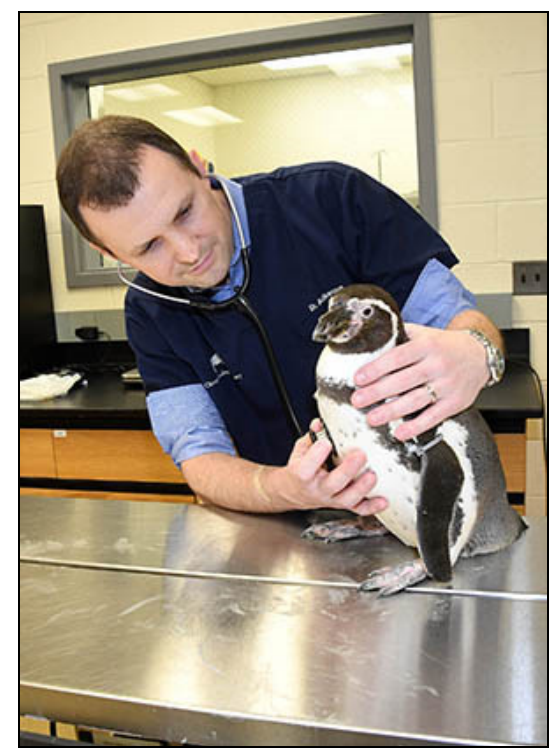

Figure 10. Adkesson tells me. Here, Adkesson examines the health of a Humboldt penguin in January 2017. His expertise with this species in zoos has inspired him to lead conservation programs in Peru for over a decade. "Frequently, zoo veterinarians are able to use the knowledge and skills they gain working with animals under professional care to benefit those in the wild," Adkesson tells me (personal communication, November 2017). Courtesy of Michael Adkesson.

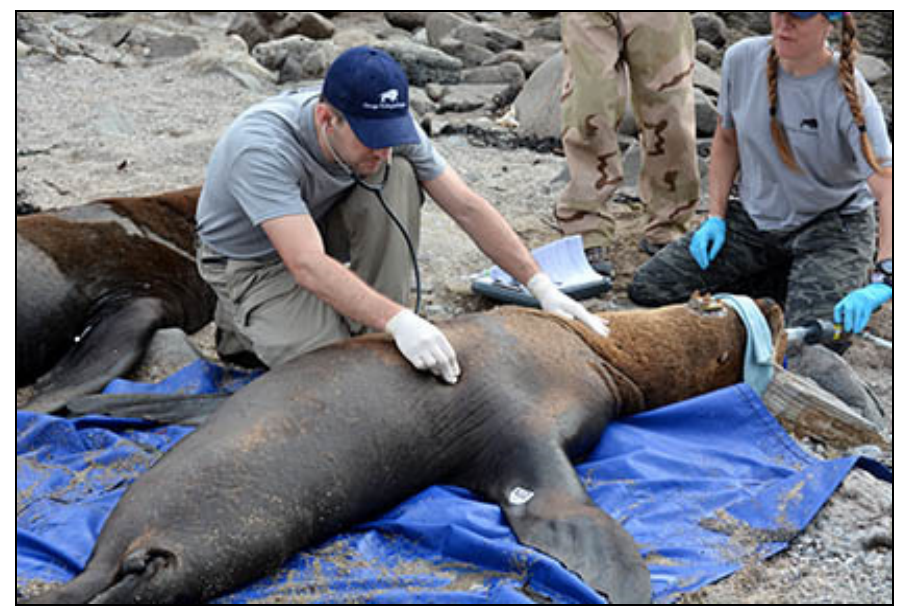

Figure 11. Adkesson examines two wild South American sea lions immobilized at Punta San Juan, Peru as part of a health assessment project to aid the conservation of this locally endangered marine mammal, November 2015. Adkesson says that, "the expertise that zoo veterinarians have developed working with animals in captivity has prepared them to safely anesthetize animals in the wild for this type of work. These animals had samples collected to assess general health, disease status, and toxicant exposure. They were also outfitted with a satellite tracking tag to determine their movements in the ocean" (personal communication, November 2017). Courtesy of Michael Adkesson.

Humanimalia: a journal of human/animal interface studies

Volume 9, Number 2 (Spring 2018) 
Alongside the zoo professionals who are applying their ex situ-based knowledge in situ, the zoo animals themselves at times serve as stand-ins for their conspecifics in the wild. The role of zoo vets in this context is to further scientific knowledge about their zoo animals as a way of contributing to the accumulation of knowledge about wild animals at large. Indeed, according to the zoo vets I spoke with for this project, collecting data about zoo animals is important not only in order to better manage zoo populations, but also to better understand their wild counterparts, thereby assisting with the in situ conservation of these wild animals. Helmick comments, accordingly, on how the work of zoo vets both in situ and ex situ supports and enhances the understanding of individual animal husbandry and population management. In her words, having a "zoo keeper staff that's knowledgeable and informed about welfare indicators they need to be looking for, having those conversations, applying best knowledge - that's going to help some animal in the wild or populations in the wild at some point" (personal communication, February 15, 2016).

Research and data collection that travels the in situ - ex situ divide has already yielded important benefits, Helmick tells me. Her strongest example is the West Nile virus. "It was a zoo vet pathologist who first identified this outbreak," she notes, explaining that the serum samples that she collected in 1982 proved critical for developing the tests used across multiple species. "We helped provide the necessary material so they could validate this test across hundreds of species. It's still the test they use today. We didn't know we would need that sample when we collected it in 1982, but we knew that one day, that sample from that captive animal was going to serve a purpose for some wild animal or some other program elsewhere" (personal communication, February 15, 2016).

Through both data and serum, medical knowledge about zoo animals has seeped into and informed other fields of medical knowledge. "Health connects all species on the planet," Tufts Veterinary Medicine Dean Philip Kosch declared in a symposium on conservation medicine (Norris 7; see also the One Health approach, as explained by veterinarian Alexander Travis). Much of the focus at the symposium was on the complex problems of emerging diseases. "There are almost no examples of emerging wildlife diseases not driven by human environmental change," a disease ecologist reported. "And few human emerging diseases don't include some domestic animal or wildlife component" (ibid.). Proponents of conservation medicine argue, accordingly, that "just as an ecological perspective can aid health workers in understanding the mechanisms of disease, adopting a medical model can benefit conservationists" (ibid.).

Irus Braverman -- Saving Species, One Individual at a Time: Zoo Veterinarians Between Welfare and Conservation 
Reintroductions. The third contribution of zoo vets to conservation and a locus of tensions between welfare and conservation is the complex process of animal reintroductions from captive to in situ locations. The idea behind zoo animal reintroductions, and a central conservation-based argument by zoo experts in support of housing animals in zoos and aquariums today, is that zoos serve as insurance populations, a source for captive members of endangered or extinct species to be reintroduced and restored in the wild (Braverman, Wild Life 125-143). Reintroductions have produced some notable conservation successes in recent decades, including the recovery of the Arabian oryx, the black-footed ferret, and the California condor (Minteer and Collins 44; see Figure 12). "It is one thing to evaluate captive-breeding programs designed to provide a steady supply of charismatic animals for zoo display," Minteer and Collins write. "It is another thing to assess those activities with the goal of recovering wildlife populations threatened in the field because of accelerating environmental change" (47). For these authors, the second instance will "ultimately compel us to rethink our responsibilities to safeguard declining species and promote ecosystem integrity and health in an increasingly dynamic environment" (48).

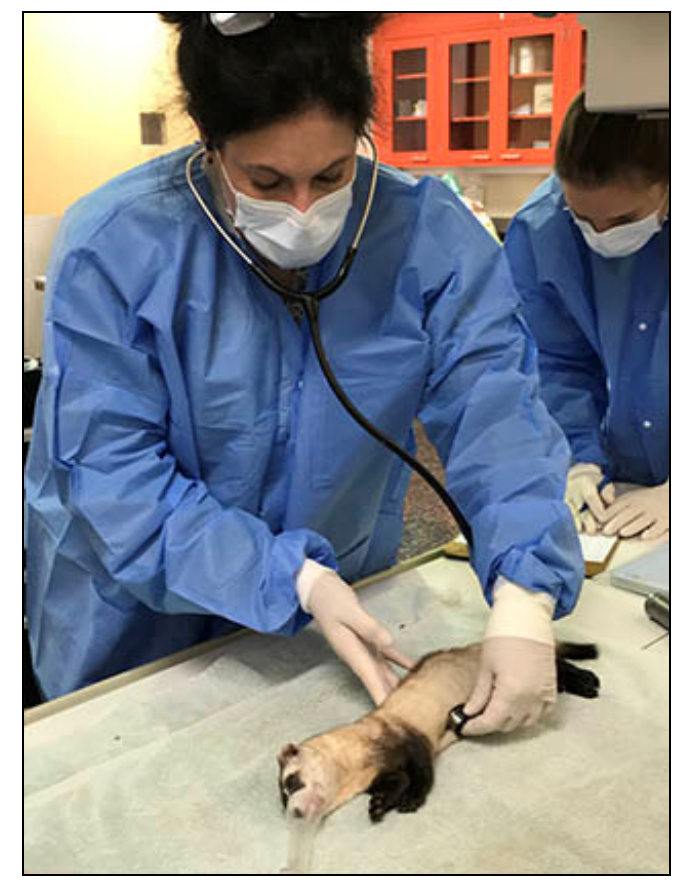

Figure 12. Helmick performs an abdominal ultrasound on an anesthetized black-footed ferret (Mustela nigripes) at the Smithsonian Conservation Biology Institute, Front Royal, VA. The black-footed ferret is one of the most endangered mammals in North America and part of a captive breeding program that reintroduces offspring to the wild. Helmick tells me that, "maintaining the health of breeding individuals as well as ensuring healthy offspring for wild release is one aspect of zoo veterinary contributions to species conservation." Photo credit: Dr. Budhan Pukazhenthi.

Humanimalia: a journal of human/animal interface studies

Volume 9, Number 2 (Spring 2018) 
But moving living organisms to new environments, even those perceived as natural or original, is risky. While much of my past research focused on risks that emerge from the training regimes designed for zoo animals undertaking this transition, the zoo vet seems to be more concerned with biosafety risks - namely, the transmission of foreign diseases and parasites. The paramount importance of biosafety in the work of the zoo vet can be gleaned from the following quote from a veterinary handbook: "the input of veterinarians in reintroduction is paramount. Disease is a major risk factor in captive wild animal management. Reintroduction of captive-bred individuals in the wild could have potentially catastrophic effects when you consider the possible dissemination and risk of an epizootic disease wiping out a population" (Kelly, Stack \& Harley 165).

The myriad concerns regarding reintroduction practices have also resulted in an intensified level of regulation in this arena. For example, in Quarantine and Health Screening Protocols for Wildlife Prior to Translocation and Release into the Wild, prominent veterinarian and founder and first Chair of the IUCN SSC Veterinary Specialist Group, Michael Woodford, states: "It is now widely recognized by wildlife veterinarians that every wild creature that is the subject of a translocation must not be regarded as just a single animal but rather as a package containing an assortment of potentially dangerous viruses [and] bacteria ... any of which may become pathogenic in a new situation, involving stresses [to] individuals in a changed environment" (7). This approach is holistic not only in that it emphasizes the interconnections between different forms of life, but also for highlighting that what looks like an individual animal is in fact an entire ecosystem, what others have also referred to as a "holobiont" (Margulis and Fester).

Conclusion. My article has explored the changing role of the zoo veterinarian in contemporary zoos, with a particular focus on North America, contemplating what these changes may teach us about the shifting management of zoo animals toward conservation. At a time of rapid transformation of both captive and wild settings, the role of the zoo veterinarian is also undergoing dramatic changes. Whereas traditionally, the vet's main concern was the welfare of individual zoo animals, it has expanded in recent decades to include not only the diversity and sustainability of zoo populations, but also the health of individuals and populations in the wild. The expansion of medical knowledge, especially about disease and its prevention, and the development of complex and integrative in situ - ex situ population management strategies, are reflected in and reinforced by the changes in the zoo veterinarian's practice.

Irus Braverman -- Saving Species, One Individual at a Time: Zoo Veterinarians Between Welfare and Conservation 
Centering on zoo vets, this article has attempted to capture the complexity of animalhuman relationship at the nexus of wild and captive settings. The study of zoo vets is especially important during this precarious time, whereby the continued livelihood of many wild animals and species in their natural ecosystems is threatened. The zoo vet is at the frontline of caring for and reproducing medical knowledge about such imperiled animals, both as individuals and as populations, and must therefore make difficult decisions about their life, death, and welfare under constantly evolving and rapidly changing conditions. Comparing and inferring between the medical conditions of different types of animals and operating in multiple settings, the zoo vet's mostly solitary practices necessitate a complex biopolitical calculus. This article has only begun to reveal the biopolitics that define the zoo vet's work, calling for further in-depth explorations in this direction.

\section{Notes}

1. Notably, the AWA does not apply to animal taxa such as birds and reptiles. For the complex and often insufficient web of law, standards, and guidelines that apply to different zoo animals in different contexts, see Braverman, Zooland, Chapter 4.

2. The distinction Helmick makes is not based on the type of animal but rather on her location and setting and on the human responsibilities that emerge thereof. In other words, for the vet, a (pet) fish is not a (wild) fish is not a(n aquarium) fish.

3. Contested by animal rights advocates and welfarists, zoos justify their continued existence also by claiming that their programs educate the general public about the importance of wildlife conservation. Enabling intimacy with exotic species, zoo animals thus serve as ambassadors for educating the public about their conspecifics in the wild (Braverman, Zooland 58, 74).

\section{Works Cited}

AZA. 2015 Annual report on conservation and science: Highlights. Web.

AAZV. (n.d.). "About us.” Web.

AAZV. Bylaws and Strategic Plan, 2012.

AAZV. Guidelines for Veterinary Advisory Group, 2001. Web.

Humanimalia: a journal of human/animal interface studies

Volume 9, Number 2 (Spring 2018) 
AAZV. Guidelines for zoo and aquarium veterinary medical programs and veterinary hospitals, 1998.

AAZV. Guidelines for zoo and aquarium veterinary medical programs and veterinary hospitals, 5th ed., 2009.

AZA. Species survival plan programs (2017). Web.

Bekoff, Marc. "Killing healthy zoo animals is wrong - and the public agrees." National Geographic. March 28, 2014. Accessed January 5, 2018. Web.

Berkovits, Anette Libeskind. Confessions of an accidental zoo curator. Tenth Planet Press, 2017.

Braverman, Irus. "Anticipating endangerment: the biopolitics of threatened species lists." BioSocieties 12.1 (2016): 132-157.

. Wild Life: The Institution of Nature. Stanford UP, 2015.

. Zooland: The Institution of Captivity. Stanford UP, 2012.

. "Zoo registrars: A bewildering bureaucracy." Duke Environmental Law E Policy Forum 21.1 (2010): 165-206.

Brogan, Jacob. "How does an aquarium veterinarian work?" Slate. May 22, 2017. Accessed January 5, 2018. Net.

Callicott, J. Baird. "Animal liberation: a triangular affair." Environmental Ethics 2 (1980): 311-328.

Cole, Linda. "A quick history of veterinary medicine." Canidae. November 4, 2014. Accessed January 5, 2018. Net.

Deem, S. L. "Role of the zoo veterinarian in the conservation of captive and free-ranging wildlife." International Zoo Yearbook 41.1 (2007): 3-11.

Grazian, David. American Zoo: A Sociological Safari. Princeton UP, 2015.

Irus Braverman -- Saving Species, One Individual at a Time: Zoo Veterinarians Between Welfare and Conservation 
Eriksen, Lars, and Maeve Kennedy. "Marius the giraffe killed at Copenhagen zoo despite worldwide protests." The Guardian. Feb. 9, 2014. Accessed January 5, 2018. Net.

Fowler, Murray E. A History of the American Association of Zoo Veterinarians. American Association of Zoo Veterinarians, 2006. Accessed January 5, 2018. Web.

Holst, Bengt. "Euthanasia of a 2 year old male giraffe at Copenhagen Zoo." Zoo. May 15, 2014. Accessed January 5, 2018. Web.

Kelly, Paul, David Stack, and Jessica Harley. "A review of the proposed reintroduction program for the far eastern leopard (Panthera pardus orientalis) and the role of conservation organizations, veterinarians, and zoos." Topics in Companion Animal Medicine 28.4 (2013): 163-166.

Law, John. "Care and killing: Tensions in veterinary practice." Heterogeneities.net. March 20, 2008. Accessed January 5, 2018. Web.

McLaughlin, Eliott C., and Peter Wilkinson. "Zoo official on Marius the giraffe: Conservation isn't always clean." CNN. Feb. 10, 2014. Accessed January 5, 2018. Web.

Margulis, Lynn, and René Fester, R., eds. Symbiosis as a Source of Evolutionary Innovation: Speciation and Morphogenesis. MIT Press, 1991.

Minteer, Ben A., and James P. Collins. "Ecological ethics in captivity: balancing values and responsibilities in zoo and aquarium research under rapid global change." Institute for Laboratory Animal Research Journal 54.1 (2013): 41-51.

McCulloch Stephen, and Michael J. Reiss. Marius the giraffe and euthanasia of zoo animals." Veterinary Ethics: Navigating Tough Cases. Siobhan Mullan and Anne Fawcett, eds. 5m Publishing, 2017.

Montgomery, Sy. The soul of an octopus: A surprising exploration into the wonder of consciousness. Astria, 2015.

Morell, Virginia. "Killing of Marius the giraffe exposes myths about zoos." National Geographic. Feb. 13, 2014. Accessed January 5, 2018. Web.

Humanimalia: a journal of human/animal interface studies

Volume 9, Number 2 (Spring 2018) 
Naess, Arne. "The deep ecological movement: Some philosophical aspects." Philosophical Inquiry 8.1-2 (1986): 10-31.

Parker, I. "Killing animals at the zoo." The New Yorker. January 10, 2017. Accessed January 5, 2018. Web.

Norris, Scott. "A new voice in conservation: Conservation medicine seeks to bring ecologists, veterinarians, and doctors together around a simple unifying concept: health." BioScience 51.1 (2001): 7-12.

RCVS. “Knowledge" (n.d.). Accessed January 5, 2018. Web.

Spelman, Lucy H., and Ted Y. Mashima, eds. The Rhino with Glue-on Shoes: And Other Surprising Stories of Zoo Vets and their Patients. Delacorte Press, 2008.

Travis, Alexander J. "Domestic dogs, gene repair, and the 'one health' approach." Gene Editing, Law, and the Environment: Life Beyond the Human. Irus Braverman, ed. Routledge, 2017. 153-168.

The Veterinary Student. "History of veterinary medicine." Iowa State University Veterinarian 2.1 (1939): 6-10. Accessed January 5, 2018. Web.

Wilkinson, Lise. Animals and disease. Cambridge UP, 1992.

Woodford, Michael H., ed. Quarantine and health screening protocols for wildlife prior to translocation and release into the wild. Published jointly by IUCN Veterinary Specialist Group, OIE, Care for the Wild, UK, and the European Association of Wildlife Veterinarians, Switzerland, 2000. Accessed January 5, 2018. Web.

Irus Braverman -- Saving Species, One Individual at a Time: Zoo Veterinarians Between Welfare and Conservation 